\title{
Characterization of Patient Interest in Provider-Based Consumer Health Information Technology: Survey Study
}

Joseph Featherall ${ }^{1}$, BS; Brittany Lapin ${ }^{2,3}$, PhD; Alexander Chaitoff ${ }^{1}$, MPH; Sonia A Havele ${ }^{4}$, BA; Nicolas Thompson ${ }^{2,3}$, MS; Irene Katzan ${ }^{1,2}$, MS, MD

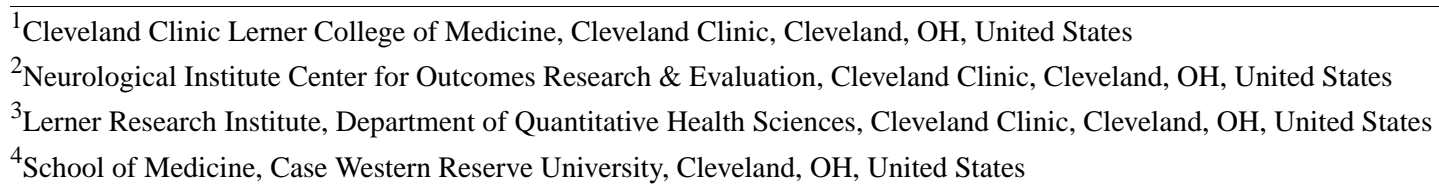

Corresponding Author:

Irene Katzan, MS, MD

Neurological Institute Center for Outcomes Research \& Evaluation

Cleveland Clinic

Mail Code $\mathrm{S} 80$

9500 Euclid Avenue

Cleveland, OH, 44195

United States

Phone: 12166365860

Fax: 12166362061

Email: katzani@ccf.org

\begin{abstract}
Background: Consumer health information technology can improve patient engagement in their health care and assist in navigating the complexities of health care delivery. However, the consumer health information technology offerings of health systems are often driven by provider rather than patient perspectives and inadequately address patient needs, thus limiting their adoption by patients. Consideration given to patients as stakeholders in the development of such technologies may improve adoption, efficacy, and consumer health information technology resource allocation.
\end{abstract}

Objective: The aims of this paper were to measure patient interest in different health system consumer health information technology apps and determine the influence of patient characteristics on consumer health information technology interest.

Methods: Patients seen at the Cleveland Clinic Neurological Institute were electronically surveyed on their interest in using different consumer health information technology apps. A self-efficacy scale, Patient Health Questionnaire-9 depression screen, and EuroQol 5 dimensions health-related quality of life scale were also completed by patients. Logistic regression was used to determine the influence of patient characteristics on interest in consumer health information technology in the categories of self-management, education, and communication.

Results: The majority of 3852 patient respondents had an interest in all technology categories assessed in the survey. The highest interest was in apps that allow patients to ask questions of providers $(3476 / 3852,90.24 \%)$ and to schedule appointments $(3211 / 3839$, $83.64 \%)$. Patient interest in consumer health information technology was significantly associated with greater depression symptoms, worse quality of life, greater health self-efficacy, and smartphone ownership ( $P<.001$ for all listed).

Conclusions: Patients should be viewed as active stakeholders in consumer health information technology development and their perspectives should consistently guide development efforts. Health systems should consider focusing on consumer health information technologies that assist patients in scheduling appointments and asking questions of providers. Patients with depression should also be considered for targeted consumer health information technology implementation. Health self-efficacy is a valid predictor of consumer health information technology interest and may play a role in the utilization of consumer health information technologies. Health systems, broadly, should put forth greater effort to understand the needs and interests of patients in the consumer health information technology development process. Consumer health information technology design and implementation may be improved by understanding which technologies patients want.

(J Med Internet Res 2018;20(4):e128) doi: 10.2196/jmir.7766 


\section{KEYWORDS}

consumer health informatics; medical informatics; self efficacy; self-management; telemedicine; patient-centered care

\section{Introduction}

\section{Background}

Health care is undergoing enormous transformation in pursuit of achieving the triple aim: enhanced individual experience of care, improved health of populations, and reduced per capita costs of care $[1,2]$. Consumer health information technology (CHIT) has been defined in a number of ways [3-5] but has recently been well described by Tao et al as consumer-centered electronic tools, technologies, apps, or systems that are interacted with directly by health consumers to provide them with data, information, recommendations, or services for promotion of health and health care [6]. Such technologies are a key component of the patient-centered transformation of health care systems $[5,7,8]$.

Implementation of CHIT is often driven by provider perspectives and available technologies rather than by the examined needs and motivations of users [5,9]. Of the largest 100 US hospitals, 66 provide mobile apps, but only $2 \%$ of patients at these hospitals are using them-an indication that health systems inadequately address the interests of patients in the CHIT design process [10]. Despite benefits in transparency and access associated with freely allowing patients to view their health data, health systems provide only limited data [11]. Focus groups have demonstrated that patients have innovative and useful perspectives as to how CHIT can improve health and ease patient workload [12-14]. Consumer perception of benefit, convenience, and integration into daily life is necessary for the successful implementation of CHIT and should be incorporated into the CHIT development process [4,15]. CHIT has been shown to improve health outcomes, but successful implementation requires that the needs of patients, that is, end users, are adequately met [3]. Overall, there is increasing recognition that health systems should systematically gather patient perspectives and use them to inform the design of CHIT [16].

The adoption of CHIT is influenced by a number of patient characteristics, but further investigation is necessary to fully characterize the CHIT needs of specific patient populations for optimum engagement and adoption [17]. For example, previous explorations have found patient portal adoption is associated with ethnic, educational, and cultural factors [18]; digital health is not used by the fastest-growing age segment of the US population, the elderly [19]; and patients who are sicker are more likely to search the internet for information and use this information during a provider visit [20]. However, these past studies have been limited in their scope, often exploring only how consumers react to already existing single CHIT solutions and not investigating the broad range of technology interests of patients. Further understanding of the technologies that patients want and the characteristics of these patients can prospectively guide strategies for providers and health systems investing in CHIT development.
Broadly, provider-based CHITs can be classified into one of 3 categories: patient-provider communications, education, and self-management technologies. Patient-provider communication technologies, including telecare, secure messaging, Web visits, and scheduling apps have demonstrated promise [21-25]. These apps improve patient convenience in accessing their health care teams. Recent data demonstrate that deficits in Web-based communication services may actually drive patients away from health systems [10]. Patient-centered prioritization of integrating communication technologies into the health system can be aided by quantifying and responding to the needs and interests of patients rather than basing technology development on data from historical technology adoption or qualitative data from small focus groups.

Electronic access to accurate patient educational resources is another established category of CHIT. Technologies that deliver educational programs to patients have demonstrated improvements in diverse outcomes, such as medication compliance [26,27], preprocedure anxiety (iPod-based modules) [28], postoperative perception of pain (educational website) [29], and plasma cholesterol (computer-based dietary workbook) [30]. During 2012, 59\% of Americans searched for health-related information on the Web [31]; a smaller, more recent study indicates that internet health information seeking is global and likely increasing [32]. The use of electronic education tools in patient care varies according to patient access to the internet and patient awareness of digital education resources $[33,34]$. Knowledge of other patient factors that impact the use of educational resources can help design, development, and implementation strategies for education-related CHIT.

Self-management technologies encompass a third category of CHITs and have been shown to improve outcomes and reduce cost $[35,36]$. These include reminder systems, physical activity trackers, physiologic data (such as blood pressure or glucose) monitors, and apps that record self-reported health status over time. Despite the growing literature on this subject, limited information currently exists on how these technologies should be designed and which patients desire such programs [37-39]. Moreover, whether or not patients desire these technologies to be offered by their health care providers, as compared with third party CHIT offerings, has yet to be explored.

In addition to gaps in the literature with regard to specific patient characteristics associated with preference for each classification of CHIT, guidance on which types of CHIT apps are more likely to be adopted by patients is not well established [40]. Despite the "perceived utility" of a CHIT being a very reliable predictor of acceptance of technology, the utility of the technology to patients is addressed in very few studies [3]. There have been survey studies regarding the factors driving acceptance of CHIT; however, these studies investigate why patients choose to accept a single technology and did not ask, "In which technologies do patients have interest [39,41-43]?" 


\section{Objectives}

The aims of this study are as follows: (1) to quantify patients' interests in CHIT by surveying patients seen in the ambulatory clinics of the Cleveland Clinic Neurological Institute and (2) to examine the influence of patient demographics, health-related quality of life, health self-efficacy, and depression on their interest in 3 categories of CHIT: patient-provider communication, educational resources, and self-management tools. This information can be used to better target the development and implementation of provider-based CHIT apps of greatest importance to patients.

\section{Methods}

\section{Survey Design}

The CHIT interest survey was designed to cover technologies that are common candidates for offerings by health systems. The technologies were grouped into 3 main categories: education, communication with health care providers, and self-management. Questions were developed by a multidisciplinary team of clinicians, researchers, and patients. Questions were evaluated by the team for content, ease of understanding, usefulness, and comprehensiveness in an iterative process and reviewed by the Neurological Institute Patient Advisory Committee for content and clarity [44]. The survey asked patients to rank their interest in various CHIT apps using a Likert scale with the following measurements: "not at all interested" (0), "not very interested" (1), "neutral" (3), "somewhat interested" (3), and "very interested" (4) (Multimedia Appendix 1). The survey was piloted, and response distributions were evaluated by the team to ensure no significant ceiling or floor effects. Internal reliability was assessed by Cronbach alpha.

To determine the impact of patient self-efficacy and current use of technology on interest in CHIT, the survey included a validated 5-item health self-efficacy questionnaire developed by Lee et al [45], as well as questions on current use of smartphones and tablet computers. The self-efficacy questionnaire included the following statements: (1) "I am confident I can have a positive effect on my health," (2) "I have set some definite goals to improve my health," (3) "I have been able to meet the goals I set for myself to improve my health," (4) "I am actively working to improve my health," and (5) "I feel that I am in control of how and what I learn about my health." Patients rated their level of agreement with these statements using a Likert scale with the following measurements: "disagree very much"(0), "disagree"(1), "neutral"(2), "agree"(3), and "agree very much"(4). The health self-efficacy score was calculated by summing the responses to the 5 questions; thus, scores of " 0 " and " 20 " indicate the lowest and highest possible health self-efficacy scores, respectively.

\section{Patient Selection and Data Collection}

Through the Knowledge Program patient-entered data collection system, patients complete the electronic questionnaires before their visits to the ambulatory clinics of the 3 pediatric and 14 adult condition-based centers of the Cleveland Clinic
Neurological Institute [46]. These centers manage patients with neurological, neurosurgical, rehabilitation, and mental health conditions. Patients were given the option to complete the questionnaires through a MyChart patient portal (Epic, Epic Systems, Verona, Wisconsin) up to 5 days before their visits. Patients not completing questionnaires beforehand completed them using tablet computers in the clinic lobby at the time of check-in for their appointment. In addition to disease-specific instruments, all patients completed the EuroQol 5 Dimensions (EQ-5D) and Patient Health Questionnaire-9 (PHQ-9) as part of their regular questionnaire set. The EQ-5D is a commonly used 5-item generic scale that measures health-related quality of life [47]. Scores are transformed into utility weights derived from the general population and range from -0.109 (state worse than death) to 1.00 (best possible health). The PHQ-9 is a 9-item depression screen that ranges from 0 to 27 , with higher scores indicating more depressive symptoms [48].

Between January 2013 and December 2015, patients seen in the 14 adult clinics who completed their questionnaires through MyChart were asked to complete the CHIT survey at the end of their regular questionnaire set. The CHIT survey was administered in each center until completed by at least 200 patients per center. As patient volume is variable across centers, a minimum response from 200 patients per center was established to ensure an adequate representation of patients. The survey was administered primarily through MyChart to avoid workflow disruptions at the time of the visit. To assess potential bias introduced by the survey delivery method, additional surveys were completed by patients seen in the Spine Center in the clinic lobby using tablet computers. Patient demographics and selected comorbid conditions (diabetes, atrial fibrillation, cancer, asthma, depression, congestive heart failure, coronary artery disease, chronic renal insufficiency, and hypertension) were identified from encounter diagnoses, problem list, or medical history sections of the electronic health record. Approximate household income was estimated based on 2010 census data by zip code. Patients 18 years of age and younger were excluded from the study. The study was approved by the Cleveland Clinic Institutional Review Board.

\section{Statistical Analysis}

Individual survey item responses were summarized using frequency count with percentage. Internal reliability of self-efficacy and the CHIT survey were assessed using Cronbach alpha. Patient characteristics are presented as mean with SD or median with interquartile range for continuous variables, and frequency count with percentage for categorical variables. For the purpose of developing a predictive model, potential uses of CHIT were organized into 3 categories: education (educational offerings and online discussion forum), communication with providers (booking appointments, asking provider questions, and entering medical history), and self-management (reminder systems, tracking physiologic data, tracking physical activity, recording lifestyle information, comparing health to others, and tracking health status information). Given the distribution of patient response, with very few patients indicating "not at all interested," high interest was defined by the multidisciplinary team as patients answering "very interested" to one or more questions within a category, whereas patients not responding 
with at least one "very interested" in the category were defined as low interest. A sensitivity analysis was conducted to define high-interest in a category as a response of "very interested" or "somewhat interested" to every question within that category. Low-interest for the sensitivity analysis was defined as a response of "neutral," "not very interested," or "not at all interested" to every question within the category.

Logistic regression models were constructed to determine univariate predictors of interest in the 3 CHIT domains. Independent predictors of the 3 outcomes were assessed using multivariable logistic regression models. Due to issues of multicollinearity, an indicator variable for any comorbidity (excluding depression) was included in the multivariable models in lieu of specific comorbidities, and smartphone ownership was included over tablet ownership as determined a priori. All potential interactions were evaluated within the final models at $P<.05$.

A subset analysis was conducted to assess potential bias introduced by surveying patients via the MyChart patient medical record portal. The 3 CHIT domain outcomes as well as individual question mean Likert scores for Spine Center patients completing the survey via MyChart were compared with those of Spine Center patients completing the survey in the lobby of the clinic using chi-squared test and Mann-Whitney $U$ test, respectively.

Additionally, univariate and multivariable logistic regression models for the 3 outcomes were constructed as described above within Spine Center patients, including the location of survey completion as a covariate, in order to test for completion location influence on patient interest. Statistical significance was established throughout at an alpha level of .05. All statistical analyses were conducted using SAS version 9.4 (SAS Institute Inc, Cary, NC).

\section{Results}

\section{Patient Characteristics}

The study cohort consisted of 3852 patients who completed a survey: 3735 in MyChart and 117 in the Spine Center lobby. The mean age of the study cohort was 57.0 (SD 14.8) years (Table 1). The majority of the cohort was white $(3115 / 3353$, $92.90 \%)$, female (2351/3852, 61.03\%), and married (2204/3351, $65.77 \%$ ). Respondents had an average of 2 comorbid conditions, with the most common being hypertension (1465/2615, 56.02\%). The majority of patients reported owning a smartphone (2640/3799, 69.49\%) and a tablet computer (2103/3809, $55.21 \%)$. 
Table 1. Clinical characteristics of the study cohort $(\mathrm{N}=3852)$.

\begin{tabular}{|c|c|}
\hline Demographics & Value \\
\hline Age (years), mean (SD) & $57.0(14.8)$ \\
\hline Female, n $(\%)$ & $2351(61.03)$ \\
\hline \multicolumn{2}{|l|}{ Race $(\mathrm{N}=\mathbf{3 3 5 3}), \mathbf{n}(\%)$} \\
\hline White & $3115(92.90)$ \\
\hline African American & $196(5.85)$ \\
\hline Other & $42(1.25)$ \\
\hline \multicolumn{2}{|l|}{ Marital status ( $\mathbf{N}=3351), \mathbf{n}(\%)$} \\
\hline Married & $2204(65.77)$ \\
\hline Single & $748(22.32)$ \\
\hline Divorced/widowed & $399(11.91)$ \\
\hline Household income (in US \$) ${ }^{\mathrm{a}}, \mathrm{N}=3326$, median (Q1-Q3) & $54,578(44,371-66,360)$ \\
\hline Any comorbid condition, $\mathrm{N}=2615, \mathrm{n}(\%)$ & $2087(79.81)$ \\
\hline Number of comorbidities $^{\mathrm{c}}$, median (Q1-Q3) & $2(1-3)$ \\
\hline \multicolumn{2}{|l|}{ Health status, median (Q1-Q3) } \\
\hline PHQ-9 ${ }^{\mathrm{d}}, \mathrm{N}=3434$ & $6(2-11)$ \\
\hline$E Q-5 D^{e}, N=3483$ & $0.78(0.60-0.83)$ \\
\hline Health efficacy score, $N=3791$ & $15(12-17)$ \\
\hline \multicolumn{2}{|l|}{ Personal mobile devices, $\mathrm{n}(\%)$} \\
\hline Smartphone ownership $(\mathrm{N}=3799)$ & $2640(69.49)$ \\
\hline Tablet ownership ( $\mathrm{N}=3809)$ & $2103(55.21)$ \\
\hline
\end{tabular}

${ }^{\mathrm{a}}$ Median household income by zip code.

${ }^{\mathrm{b}} \mathrm{Q}$ : first quartile, Q3: third quartile.

${ }^{\mathrm{c}}$ Comorbid conditions include diabetes, atrial fibrillation, cancer, coronary artery disease, chronic renal insufficiency, and hypertension.

${ }^{\mathrm{d}}$ PHQ-9: Patient Health Questionnaire-9.

${ }^{\mathrm{e}}$ EQ-5D: EuroQol 5 Dimensions.

\section{Health Self-Efficacy}

Internal reliability of this scale was high (Cronbach alpha=.845). The majority of patients responded affirmatively to all self-efficacy items, except the ability to meet health goals. Regarding meeting health goals, only 1663 out of 3815 (43.59\%) respondents indicated that they agreed with the health efficacy statement. Regarding ability to have a positive effect on one's health, 3274 out of 3825 (85.59\%) patients indicated perceived self-efficacy in this area $(1597 / 3825,41.75 \%$, "Agree" and 1677/3825, 43.84\%, “Agree very much”).

\section{Consumer Health Information Technology Interest}

Internal reliability of the CHIT survey was good, with Cronbach alpha of .832 for education, .762 for self-management, and .898 for communication. The majority of patients indicated interest in all of the CHIT categories asked in the survey (Figure 1). Patients expressed the greatest interest in the communication category, specifically booking appointments (2227/3839, $58.01 \%$, "very interested" and 984/3839, 25.63\%, "interested") and asking their provider questions $(2570 / 3852,66.72 \%$, "very interested" and 906/3852, 23.52\%, "interested").
There were no categories in which a majority of subjects reported being disinterested in a service potentially offered by health technologies. However, greater than half of subjects reported neutral interest or less when asked about their interest in a technology that acted as a reminder system (2207/3845, $57.40 \%$ ) or that would allow subjects to compare their health with others $(1958 / 3848,50.88 \%)$.

The majority of patients $(2729 / 3838,71.10 \%)$ were very interested in one of the items comprising the domain of communication, with $50.50 \%$ (1938/3838) being very interested in the domain of self-management and over a third of patients $(1362 / 3843,33.44 \%)$ being very interested in one of the items comprising the domain of education.

In the unadjusted analysis, patients were significantly more likely to be "very interested" in all 3 domains if they were female, African American (as compared with Caucasian), single (as compared with married), owned a smartphone, and had higher depression and health self-efficacy scores. They were less likely to be "very interested" in CHIT if they were older, had better health-related quality-of-life, or if they had coronary artery disease or hypertension (data not shown). 
After adjustment for patient characteristics, however, only higher depression ratings, higher health self-efficacy scores, and smartphone ownership remained significant predictors of patient interest in all 3 technology categories: education, communication, and self-management (Table 2). Health-related quality of life was also an independent predictor of lack of interest in education technologies (odds ratio [OR] 0.92, 95\% CI 0.86-0.98 per 0.1 increase), and older age was an independent predictor of lack of interest in self-management technologies (OR 0.89, 95\% CI 0.81-0.97 per decade increase). No interaction effects were found.

Figure 1. Response distribution to consumer health information technology interest survey questions. Response distributions (n) are shown for the level of interest to each question on the health information technology survey. Questions are grouped by category: education, communication, and self-management.

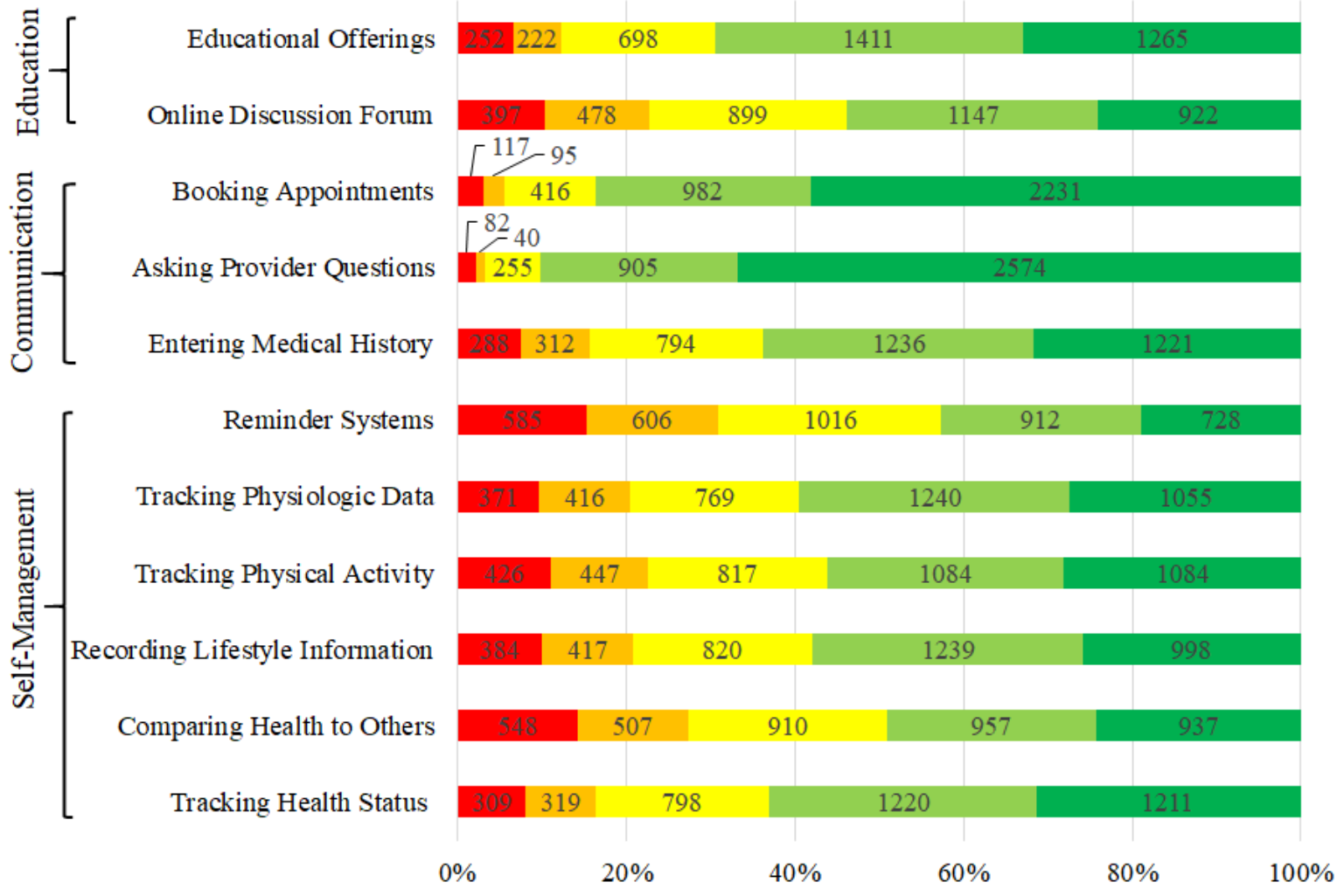

$\square$ Not at all interested $\square$ Not very interested $₫$ Neutral $\square$ Somewhat interested $\square$ Very interested 
Table 2. Multivariable predictors of consumer health information technology (CHIT) outcomes: education, communication, and self-management.

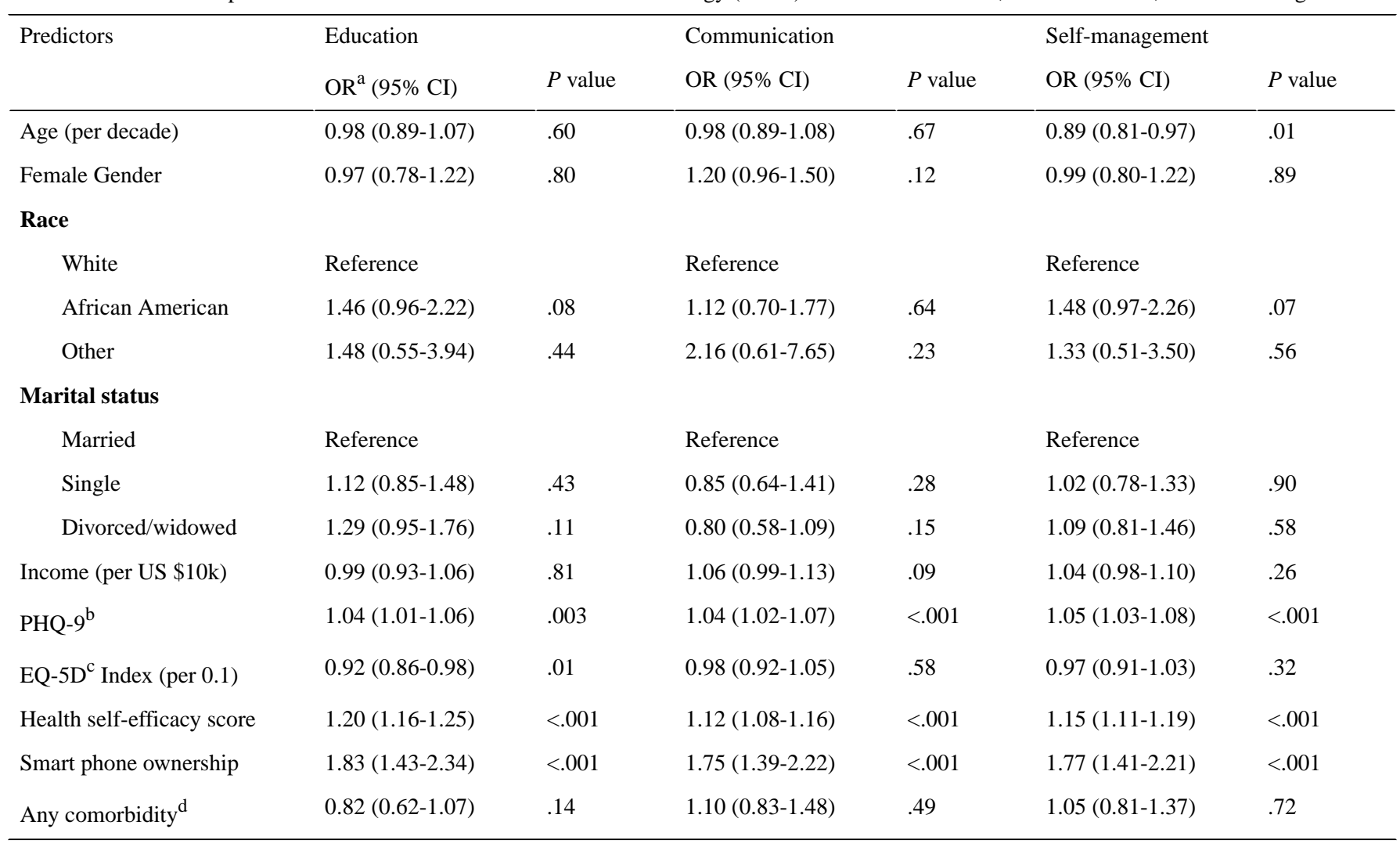

aR: odds ratio.

${ }^{\mathrm{b}} \mathrm{PHQ}-9$ : Patient Health Questionnaire-9.

${ }^{\mathrm{c}}$ EQ-5D: Euroqol 5 Dimensions.

${ }^{\mathrm{d}}$ Comorbid conditions include diabetes, atrial fibrillation, cancer, coronary artery disease, chronic renal insufficiency, and hypertension.

\section{Sensitivity Analysis}

Analyses were replicated after defining the outcome of interest in CHIT categories as a response of "somewhat interested" or "very interested" for every question within each category. Using this definition, 50.42\% (1938/3843) of patients expressed interest in the education questions, $58.52 \%(2246 / 3838)$ in the communication questions, and $22.00 \%$ (844/3838) in the self-management questions. The independent predictors of interest in education and self-management remained the same as those presented in Table 2. Predictors for communication also remained the same, with the addition of decreasing age (OR 0.89, 95\% CI 0.81-0.97 per decade increase).

\section{Subset Analysis}

To assess whether completion location biased the study results, 117 out of $904(12.9 \%)$ patients seen in the Spine Center completed the technology survey in the lobby, and results were compared with 787 out of $904(87.1 \%)$ patients who completed the survey using MyChart before their Spine Center visit. In the unadjusted analysis, there were no significant differences in interest in CHIT regarding education or self-management (data not shown). Regarding communication questions, 513 of the 787 patients $(65.2 \%)$ who completed the survey via MyChart indicated they were "very interested" in asking their provider questions compared with 64 of the $117(54.7 \%)$ waiting room responders $(P=.03)$. Similarly, 441 of $782(56.4 \%)$ MyChart respondents expressed they were "very interested" in booking appointments versus 50 of the $117(42.7 \%)$ patients in the waiting room $(P=.006)$. After adjustment for patient characteristics, survey completion through MyChart was not a significant predictor of interest in communication (OR 1.81, 95\% CI 0.85-3.85; $P=.12$ ).

\section{Discussion}

\section{Principal Findings}

CHIT is a promising strategy to enhance individual experience of care and improve the health of populations. CHIT has been demonstrated to engage patients, enhance clinical interventions, and improve health outcomes [49,50]. Focusing on CHIT approaches that are of greatest interest to patients would allow better allocation of resources by health care institutions that are struggling to contain costs and provide superior care in the current environment of reducing reimbursements. Our study found that over half of patient respondents are interested in CHIT apps that provide education, methods to communicate with healthcare providers, and self-management tools. The greatest interest is in CHIT apps that allow patients to ask questions of their health providers and to schedule appointments. CHIT apps that were of lowest interest to respondents were reminder systems and those that provided the ability to compare health status with others with the same condition.

Historically, the design of CHIT has been largely guided by provider attributes, financial incentives, and provider's 
perceptions of patient needs rather than the needs and interests of patients themselves [5,17,51-53]. While a recent global survey indicated that only $8 \%$ of hospital-produced mobile apps offer the ability to book appointments [10], this study indicates that $83.65 \%(3213 / 3841)$ of current health system patients are interested in this functionality (Figure 1). Current estimates indicate that $7 \%$ of patients have changed their health systems because of deficits in online services [10]. This study is currently the largest survey of patient interest in provider-based CHIT and addresses a broader range of technologies than any previous surveys, providing actionable information for health systems working to address the provider-based CHIT gap.

\section{Quality of Life (EQ-5D) and Education Interest}

In this study, patients with worse health-related quality of life, as assessed by EQ-5D, had a greater interest in educational technologies than patients with better quality of life. This is consistent with prior literature that sicker patients are more likely to search for health information [20]. When targeting CHIT strategies for patients with poor quality of life, education-related CHIT apps may be especially beneficial.

\section{Depression (PHQ-9) and Overall Interest}

Patients with increasingly severe depression, as assessed with the PHQ-9 scale, demonstrated increasing interest in all 3 CHIT categories: education, communication, and self-management. It has been established that patients with depression may prefer treatment that does not require face-to-face interaction [54] Recent trials of mobile apps have also demonstrated efficacy in managing depression [55-57]. Although, in the past decade, there has been a sharp increase in depression and the depression CHIT market, the large majority of these apps are neither evidence-based nor affiliated with any established medical institution [58]. Depression, despite being a leading global cause of disability, remains underdiagnosed and undertreated [59] The high interest of patients with depression in this study and the lack of widely available evidence-based CHITs for depression behoove providers to carefully consider this population for focused CHIT development efforts.

\section{Health Self-Efficacy and Overall Interest}

General self-efficacy, the belief in one's competence to cope with a broad range of stressful or challenging demands, correlates well with self-regulation, coping strategies, and well-being [60]. Health, nutrition, physical exercise, and alcohol resistance self-efficacies are valid predictors of constructive health-related behaviors [61-63]; health self-efficacy, specifically, has been shown to influence health information-seeking behaviors [45,64]. Perceived difficulty of use decreases patient acceptance of CHITs [3]. CHITs are often promoted as mechanisms for increasing patient "empowerment," "engagement," "activation," and so on [65], but little data exist on the association between self-efficacy and interest in using CHIT [3]. Our data suggest that the underlying attitudes of patients toward their health influence the desire to use such technologies. Health self-efficacy may explain the underlying attitudes that assist patients in overcoming the learning curve required to adopt CHITs. Such a concept has practical implications in that such underlying attitudes may explain some of the variability in the efficacy of CHITs observed in trials within different populations [6]. Developers may also consider targeting high self-efficacy users for increasing the likelihood of a successful CHIT implementation.

\section{Smartphone Ownership and Overall Interest}

Mobile health apps are poised to become a determining factor in restructuring old health care services and systems still based on physical relationships between patients and providers [66,67]. The data from this study indicate that smartphone use is a strong predictor of CHIT interest. Supporting this finding is a recent patient survey, in which $86 \%$ of respondents demonstrated interest in using a mobile app to improve their health [68]. Despite widespread enthusiasm and public interest, national survey data demonstrate that mobile apps offered by providers were lower rated by users and are not aligned with patient wants or needs [10]. Due to their ease of use, smartness, accessibility, mobility, and connectivity, smartphones are an effective and consumer-oriented technology platform; however, health systems consistently lag behind in mobile technology offerings [69]. These data, together, suggest that there exists a large opportunity for providers to improve their mobile offerings, focusing on usability and the functionalities patients desire.

\section{Limitations}

This study has some limitations. The survey was administered to patients seen within the Cleveland Clinic Neurological Institute. The study sample was largely white (3115/3852, $92.90 \%$ ), with a moderately high median annual household income (US \$54,578); centers with different demographics may have different findings. However, these clinics see patients with a broad range of conditions, spanning from back pain to neurodegenerative disorders to psychiatric conditions. Moreover, this study assesses the CHIT interest of current health care users rather than the population-based surveys that are often used to assess attitudes and preferences, and thus, may more accurately reflect the preferences of current patients. Another limitation is the deployment of surveys via the MyChart patient portal, introducing possible responder bias as respondents using the patient portal may be more apt to use health technologies. However, there was no significant difference in patient interest in using CHIT between respondents receiving the survey via the patient portal and the sample of respondents completing the survey in the clinic lobby.

\section{Future Directions}

This study provides insight into the interests and needs of current health system patients. This study also demonstrates how such information can be used to model patient interest to target technology offerings of providers. Future studies should include the development of more sophisticated predictive models; continuing to identify subpopulations defined by disease states, preferences, and need attributes will further optimize CHIT implementations.

\section{Conclusions}

Health care is under pressure to improve outcomes and decrease cost; CHITs provide a promising solution. CHIT developers often pay minimal attention to patients' motivations, needs, and psychosocial characteristics [70]. Such oversights may lead to 
underutilization of provider-based CHIT. In order to solve this problem, patients should be recognized as full stakeholders in health information systems and their perspectives should be systematically incorporated into development efforts [71]. Due to high patient interest, CHIT developers and health system clinician leaders should consider focusing CHIT development toward smartphone platforms and developing CHIT apps that allow patients to schedule appointments and to ask questions of their providers [72,73]. Patients with depression have a high interest in CHITs and thus may benefit from provider offerings of evidence-based CHITs. Health self-efficacy is an independent predictor of CHIT interest and should be considered in future attempts to explain CHIT adoption and efficacy patterns.

\section{Acknowledgments}

The authors wish to thank Ya-Ling Lu, MLIS, PhD, Staff Informationist, National Institutes of Health Library for reviewing the literature.

\section{Conflicts of Interest}

None declared.

\section{Multimedia Appendix 1}

Consumer health information technology interest survey.

[PDF File (Adobe PDF File), 30KB-Multimedia Appendix 1]

\section{References}

1. Berwick DM, Nolan TW, Whittington J. The triple aim: care, health, and cost. Health Aff (Millwood) 2008;27(3):759-769 [FREE Full text] [doi: 10.1377/hlthaff.27.3.759] [Medline: 18474969]

2. Sheikh A, Sood HS, Bates DW. Leveraging health information technology to achieve the "triple aim" of healthcare reform. J Am Med Inform Assoc 2015 Jul;22(4):849-856 [FREE Full text] [doi: 10.1093/jamia/ocv022] [Medline: 25882032]

3. Or CK, Karsh B. A systematic review of patient acceptance of consumer health information technology. J Am Med Inform Assoc 2009 Aug;16(4):550-560 [FREE Full text] [doi: 10.1197/jamia.M2888] [Medline: 19390112]

4. Improving Consumer Health IT Application Development: Lessons From Other Industries URL: https://healthit.ahrq.gov/ sites/default/files/docs/citation/background report final.pdf[WebCite Cache ID 6pKb4Diis]

5. Eysenbach G. Consumer health informatics. Br Med J 2000 Jun 24;320(7251):1713-1716 [FREE Full text] [Medline: 10864552]

6. Tao D, Wang T, Wang T, Liu S, Qu X. Effects of consumer-oriented health information technologies in diabetes management over time: a systematic review and meta-analysis of randomized controlled trials. J Am Med Inform Assoc 2017 Sep 01;24(5):1014-1023. [doi: 10.1093/jamia/ocx014] [Medline: 28340030]

7. Agarwal R, Khuntia J. 2009. Personal Health Information Management and the Design of Consumer Health Information Technology URL: https://healthit.ahrq.gov/sites/default/files/docs/page/09-0075-EF 1.pdf[WebCite Cache ID 6pKa4bHX8]

8. Wolff JL, Darer JD, Larsen KL. Family caregivers and consumer health information technology. J Gen Intern Med 2016 Jan;31(1):117-121 [FREE Full text] [doi: 10.1007/s11606-015-3494-0] [Medline: 26311198]

9. Knight EP, Shea K. A patient-focused framework integrating self-management and informatics. J Nurs Scholarsh 2014 Mar;46(2):91-97. [doi: 10.1111/jnu.12059] [Medline: 24354997]

10. Kalis B, Froelich J, Burke A, Warren M. Accenture. 2016. Losing Patience: Why Healthcare Providers Need to Up Their Mobile Game URL: https://www.accenture.com/t20160629T221243 w /us-en/ acnmedia/PDF-24/

Accenture-Losing-Patience.pdf [accessed 2017-03-29] [WebCite Cache ID 6pKas3SIK]

11. Mandl KD, Kohane IS. Time for a patient-driven health information economy? N Engl J Med 2016 Jan 21;374(3):205-208 [FREE Full text] [doi: 10.1056/NEJMp1512142] [Medline: 26789868]

12. Zulman DM, Jenchura EC, Cohen DM, Lewis ET, Houston TK, Asch SM. How can eHealth technology address challenges related to multimorbidity? Perspectives from patients with multiple chronic conditions. J Gen Intern Med 2015 Feb 18;30(8):1063-1070. [doi: 10.1007/s11606-015-3222-9] [Medline: 25691239]

13. Walker J, Ahern DK, Le LX, Delbanco T. Insights for internists: "I want the computer to know who I am". J Gen Intern Med 2009 Jun;24(6):727-732 [FREE Full text] [doi: 10.1007/s11606-009-0973-1] [Medline: 19412641]

14. Ancker JS, Witteman HO, Hafeez B, Provencher T, Van de Graaf M, Wei E. "You get reminded you're a sick person": personal data tracking and patients with multiple chronic conditions. J Med Internet Res 2015;17(8):e202 [FREE Full text] [doi: 10.2196/jmir.4209] [Medline: 26290186]

15. Jimison H, Gorman P, Woods S, Nygren P, Walker M, Norris S, et al. Barriers and drivers of health information technology use for the elderly, chronically ill, and underserved. Evid Rep Technol Assess (Full Rep) 2008 Nov(175):1-1422. [Medline: 19408968] 
16. Abelson J, Wagner F, DeJean D, Boesveld S, Gauvin F, Bean S, et al. Public and patient involvement in health technology assessment: a framework for action. Int J Technol Assess Health Care 2016 Jan;32(4):256-264. [doi: 10.1017/S0266462316000362] [Medline: 27670693]

17. Irizarry T, DeVito DA, Curran CR. Patient portals and patient engagement: a state of the Science review. J Med Internet Res 2015;17(6):e148 [FREE Full text] [doi: 10.2196/jmir.4255] [Medline: 26104044]

18. Goldzweig CL, Orshansky G, Paige NM, Towfigh AA, Haggstrom DA, Miake-Lye I, et al. Electronic patient portals: evidence on health outcomes, satisfaction, efficiency, and attitudes: a systematic review. Ann Intern Med 2013 Nov 19;159(10):677-687. [doi: 10.7326/0003-4819-159-10-201311190-00006] [Medline: 24247673]

19. Levine DM, Lipsitz SR, Linder JA. Trends in seniors' use of digital health technology in the United States, 2011-2014. J Am Med Assoc 2016 Aug 2;316(5):538-540. [doi: 10.1001/jama.2016.9124] [Medline: 27483069]

20. Houston TK, Allison JJ. Users of Internet health information: differences by health status. J Med Internet Res 2002 Dec;4(2):E7 [FREE Full text] [doi: 10.2196/jmir.4.2.e7] [Medline: 12554554$]$

21. Kroenke K, Theobald D, Wu J, Norton K, Morrison G, Carpenter J, et al. Effect of telecare management on pain and depression in patients with cancer: a randomized trial. J Am Med Assoc 2010 Jul 14;304(2):163-171 [FREE Full text] [doi: 10.1001/jama.2010.944] [Medline: 20628129]

22. Tang PC, Overhage JM, Chan AS, Brown NL, Aghighi B, Entwistle MP, et al. Online disease management of diabetes: engaging and motivating patients online with enhanced resources-diabetes (EMPOWER-D), a randomized controlled trial. J Am Med Inform Assoc 2013 May 1;20(3):526-534 [FREE Full text] [doi: 10.1136/amiajnl-2012-001263] [Medline: 23171659]

23. Kruse CS, Bolton K, Freriks G. The effect of patient portals on quality outcomes and its implications to meaningful use: a systematic review. J Med Internet Res 2015;17(2):e44 [FREE Full text] [doi: 10.2196/jmir.3171] [Medline: 25669240]

24. Tsiligianni I, Kocks J, Tzanakis N, Siafakas N, van der Molen T. Factors that influence disease-specific quality of life or health status in patients with COPD: a review and meta-analysis of Pearson correlations. Prim Care Respir J 2011 Sep;20(3):257-268 [FREE Full text] [doi: 10.4104/pcrj.2011.00029] [Medline: 21472192]

25. Or CK, Tao D, Wang H. The effectiveness of the use of consumer health information technology in patients with heart failure: a meta-analysis and narrative review of randomized controlled trials. J Telemed Telecare 2017 Jan;23(1):155-166. [doi: 10.1177/1357633X15625540] [Medline: 26759365]

26. Lewis D. Computer-based approaches to patient education: a review of the literature. J Am Med Inform Assoc 1999;6(4):272-282 [FREE Full text] [Medline: 10428001]

27. Denizard-Thompson NR, Singh S, Stevens SR, Miller DP, Wofford JL. iPod ${ }^{\mathrm{TM}}$ technology for teaching patients about anticoagulation: a pilot study of mobile computer-assisted patient education. Prim Health Care Res Dev 2012 Jan;13(1):42-47. [doi: 10.1017/S146342361100034X] [Medline: 21854695]

28. Shaw MJ, Beebe TJ, Tomshine PA, Adlis SA, Cass OW. A randomized, controlled trial of interactive, multimedia software for patient colonoscopy education. J Clin Gastroenterol 2001 Feb;32(2):142-147. [Medline: 11205650]

29. Goldsmith DM, Safran C. Using the Web to reduce postoperative pain following ambulatory surgery. Proc AMIA Symp 1999:780-784 [FREE Full text] [Medline: $\underline{\text { 10566466] }}$

30. Clark M, Ghandour G, Miller NH, Taylor CB, Bandura A, DeBusk RF. Development and evaluation of a computer-based system for dietary management of hyperlipidemia. J Am Diet Assoc 1997 Feb;97(2):146-150. [doi:

10.1016/S0002-8223(97)00040-0] [Medline: 9020241]

31. Fox S, Duggan M. Pew Internet. 2013. URL: http://www.pewinternet.org/2013/01/15/health-online-2013/[WebCite Cache ID $6 \mathrm{pKcBWOIW]}$

32. Moreland J, French TL, Cumming GP. The prevalence of online health information seeking among patients in Scotland: a cross-sectional exploratory study. JMIR Res Protoc 2015;4(3):e85 [FREE Full text] [doi: 10.2196/resprot.4010] [Medline: 26177562]

33. Horton KM, Garland MR, Fishman EK. The Internet as a potential source of information about radiological procedures for patients. J Digit Imaging 2000 Feb;13(1):46-47 [FREE Full text] [Medline: 10696601]

34. Robinson C, Flowers CW, Alperson BL, Norris KC. Internet access and use among disadvantaged inner-city patients. J Am Med Assoc 1999 Mar 17;281(11):988-989. [Medline: 10086432]

35. Coye MJ, Haselkorn A, DeMello S. Remote patient management: technology-enabled innovation and evolving business models for chronic disease care. Health Aff (Millwood) 2009;28(1):126-135 [FREE Full text] [doi: 10.1377/hlthaff.28.1.126] [Medline: 19124862]

36. Panagioti M, Richardson G, Small N, Murray E, Rogers A, Kennedy A, et al. Self-management support interventions to reduce health care utilisation without compromising outcomes: a systematic review and meta-analysis. BMC Health Serv Res 2014;14:356 [FREE Full text] [doi: 10.1186/1472-6963-14-356] [Medline: 25164529]

37. Pearson M, Mattke S, Shaw R, Ridgely M. 2007. Patient Self-Management Support Programs: An Evaluation URL: http:/ /www.ahrq.gov/sites/default/files/wysiwyg/research/findings/final-reports/ptmgmt/ptmgmt.pdf[WebCite Cache ID $\underline{6 \mathrm{pKcNDXxt}]}$

38. Lyles C, Schillinger D, Sarkar U. Connecting the dots: health information technology expansion and health disparities. PLoS Med 2015 Jul;12(7):e1001852 [FREE Full text] [doi: 10.1371/journal.pmed.1001852] [Medline: 26172977] 
39. Huygens MW, Vermeulen J, Swinkels IC, Friele RD, van Schayck OC, de Witte LP. Expectations and needs of patients with a chronic disease toward self-management and eHealth for self-management purposes. BMC Health Serv Res 2016 Jul 08;16:232 [FREE Full text] [doi: 10.1186/s12913-016-1484-5] [Medline: 27391471]

40. Arsand E, Demiris G. User-centered methods for designing patient-centric self-help tools. Inform Health Soc Care 2008 Sep;33(3):158-169. [doi: 10.1080/17538150802457562] [Medline: 18850399]

41. Wang SH. Web-based medical service: technology attractiveness, medical creditability, information source, and behavior intention. J Med Internet Res 2017 Aug 02;19(8):e285 [FREE Full text] [doi: 10.2196/jmir.8114] [Medline: 28768608]

42. Cranen K, Groothuis-Oudshoorn CG, Vollenbroek-Hutten MM, IJzerman MJ. Toward patient-centered telerehabilitation design: understanding chronic pain patients' preferences for web-based exercise telerehabilitation using a discrete choice experiment. J Med Internet Res 2017 Jan 20;19(1):e26 [FREE Full text] [doi: 10.2196/jmir.5951] [Medline: 28108429]

43. Jenssen BP, Mitra N, Shah A, Wan F, Grande D. Using digital technology to engage and communicate with patients: a survey of patient attitudes. J Gen Intern Med 2016 Jan;31(1):85-92. [doi: 10.1007/s11606-015-3517-x] [Medline: 26385117]

44. Hickam D, Totten A, Berg A, Rader K, Goodman S, Newhouse R. 2013. The PCORI Methodology Report URL: http:/ /www.pcori.org/research-results/research-methodology [accessed 2017-03-29] [WebCite Cache ID 6pKcSm0FJ]

45. Lee SY, Hwang H, Hawkins R, Pingree S. Interplay of negative emotion and health self-efficacy on the use of health information and its outcomes. Communic Res 2008 Apr 14;35(3):358-381. [doi: 10.1177/0093650208315962]

46. Katzan I, Speck M, Dopler C, Urchek J, Bielawski K, Dunphy C, et al. The Knowledge Program: an innovative, comprehensive electronic data capture system and warehouse. AMIA Annu Symp Proc 2011;2011:683-692 [ㅍREE Full text] [Medline: 22195124]

47. Shaw JW, Johnson JA, Coons SJ. US valuation of the EQ-5D health states: development and testing of the D1 valuation model. Med Care 2005 Mar;43(3):203-220. [Medline: 15725977]

48. Kroenke K, Spitzer RL, Williams JB. The PHQ-9: validity of a brief depression severity measure. J Gen Intern Med 2001 Sep;16(9):606-613 [FREE Full text] [Medline: 11556941]

49. Jha AK. Health information technology: on the cusp of healthcare transformation. Am J Manag Care 2013 Nov;19(10 Spec No):SP335-SP336 [FREE Full text] [Medline: 24511887]

50. Gibbons C, Wilson R, Samal L, Lehmann C. 2009. Impact of Consumer Health Informatics Applications URL: https:/ /www.ahrq.gov/downloads/pub/evidence/pdf/chiapp/impactchia.pdf[WebCite Cache ID 6pKcpeMeh]

51. Keselman A, Logan R, Smith CA, Leroy G, Zeng-Treitler Q. Developing informatics tools and strategies for consumer-centered health communication. J Am Med Inform Assoc 2008;15(4):473-483 [FREE Full text] [doi: 10.1197/jamia.M2744] [Medline: 18436895]

52. Audet A, Squires D, Doty MM. Where are we on the diffusion curve? Trends and drivers of primary care physicians' use of health information technology. Health Serv Res 2014 Feb;49(1 Pt 2):347-360 [FREE Full text] [doi: 10.1111/1475-6773.12139] [Medline: 24358958]

53. Menefee HK, Thompson MJ, Guterbock TM, Williams IC, Valdez RS. Mechanisms of communicating health information through Facebook: implications for consumer health information technology design. J Med Internet Res 2016 Aug 11;18(8):e218 [FREE Full text] [doi: 10.2196/jmir.5949] [Medline: 27515151]

54. Gustafson DH, Hawkins RP, Boberg EW, McTavish F, Owens B, Wise M, et al. CHESS: 10 years of research and development in consumer health informatics for broad populations, including the underserved. Int J Med Inform 2002 Nov 12;65(3):169-177. [Medline: $\underline{12414016]}$

55. Proudfoot J, Clarke J, Birch M, Whitton AE, Parker G, Manicavasagar V, et al. Impact of a mobile phone and web program on symptom and functional outcomes for people with mild-to-moderate depression, anxiety and stress: a randomised controlled trial. BMC Psychiatry 2013;13:312 [FREE Full text] [doi: 10.1186/1471-244X-13-312] [Medline: 24237617]

56. Agyapong VI, Juhás M, Ohinmaa A, Omeje J, Mrklas K, Suen VY, et al. Randomized controlled pilot trial of supportive text messages for patients with depression. BMC Psychiatry 2017 Aug 02;17(1):286 [FREE Full text] [doi: 10.1186/s12888-017-1448-2] [Medline: 28768493]

57. Watts S, Mackenzie A, Thomas C, Griskaitis A, Mewton L, Williams A, et al. CBT for depression: a pilot RCT comparing mobile phone vs. computer. BMC Psychiatry 2013;13:49 [FREE Full text] [doi: 10.1186/1471-244X-13-49] [Medline: 23391304]

58. Shen N, Levitan M, Johnson A, Bender JL, Hamilton-Page M, Jadad AA, et al. Finding a depression app: a review and content analysis of the depression app marketplace. JMIR Mhealth Uhealth 2015;3(1):e16 [FREE Full text] [doi: 10.2196/mhealth.3713] [Medline: 25689790]

59. Thombs BD, Ziegelstein RC. Does depression screening improve depression outcomes in primary care? Br Med J 2014 Feb 04;348:g1253. [Medline: 24496211]

60. Luszczynska A, Scholz U, Schwarzer R. The general self-efficacy scale: multicultural validation studies. J Psychol 2005 Sep;139(5):439-457. [doi: 10.3200/JRLP.139.5.439-457] [Medline: 16285214]

61. Health-Specific Self-Efficacy Scales. 2009. URL: https://userpage.fu-berlin.de/health/healself.pdf [accessed 2017-10-03] [WebCite Cache ID 6twhI7xQR]

62. Self-Efficacy and Health Behaviours. 1995. URL: http://userpage.fu-berlin.de/gesund/publicat/conner9.htm [accessed 2017-10-03] [WebCite Cache ID 6twhQCnmM] 
63. Sheeran P, Maki A, Montanaro E, Avishai-Yitshak A, Bryan A, Klein WM, et al. The impact of changing attitudes, norms, and self-efficacy on health-related intentions and behavior: a meta-analysis. Health Psychol 2016 Nov;35(11):1178-1188. [doi: 10.1037/hea0000387] [Medline: 27280365]

64. Deng Z, Liu S. Understanding consumer health information-seeking behavior from the perspective of the risk perception attitude framework and social support in mobile social media websites. Int J Med Inform 2017 Sep;105:98-109. [doi: 10.1016/j.ijmedinf.2017.05.014] [Medline: 28750916]

65. Barello S, Triberti S, Graffigna G, Libreri C, Serino S, Hibbard J, et al. eHealth for patient engagement: a systematic review. Front Psychol 2015;6:2013 [FREE Full text] [doi: 10.3389/fpsyg.2015.02013] [Medline: 26779108]

66. Silva BM, Rodrigues JJ, de la Torre Díez I, López-Coronado M, Saleem K. Mobile-health: a review of current state in 2015. J Biomed Inform 2015 Aug;56:265-272. [doi: 10.1016/j.jbi.2015.06.003] [Medline: 26071682]

67. Steinhubl SR, Muse ED, Topol EJ. The emerging field of mobile health. Sci Transl Med 2015 Apr 15;7(283):283rv3. [doi: 10.1126/scitranslmed.aaa3487] [Medline: 25877894]

68. Ramirez V, Johnson E, Gonzalez C, Ramirez V, Rubino B, Rossetti G. Assessing the use of mobile health technology by patients: an observational study in primary care clinics. JMIR Mhealth Uhealth 2016;4(2):e41 [FREE Full text] [doi: 10.2196/mhealth.4928] [Medline: 27095507]

69. Lee J. Future of the smartphone for patients and healthcare providers. Healthc Inform Res 2016 Jan;22(1):1-2 [FREE Full text] [doi: 10.4258/hir.2016.22.1.1] [Medline: 26893944]

70. Marquard JL, Zayas-Cabán T. Commercial off-the-shelf consumer health informatics interventions: recommendations for their design, evaluation and redesign. J Am Med Inform Assoc 2012;19(1):137-142 [FREE Full text] [doi: 10.1136/amiajnl-2011-000338] [Medline: 21727206]

71. Hunt JS, Gibson RF, Whittington J, Powell K, Wozney B, Knudson S. Guide for developing an information technology investment road map for population health management. Popul Health Manag 2015 Jun;18(3):159-171. [doi: 10.1089/pop.2014.0092] [Medline: 25607932]

72. Zhao P, Yoo I, Lavoie J, Lavoie BJ, Simoes E. Web-based medical appointment systems: a systematic review. J Med Internet Res 2017 Apr 26;19(4):e134 [FREE Full text] [doi: 10.2196/jmir.6747] [Medline: 28446422]

73. Uei S, Tsai C, Kuo Y. The effect of telehealth systems and satisfaction with health expenditure among patients with metabolic syndrome. Technol Health Care 2016 Apr 29;24(Suppl 2):S527-S532. [doi: 10.3233/THC-161178] [Medline: 27163314]

\author{
Abbreviations \\ CHIT: consumer health information technology \\ EQ-5D: EuroQol 5 Dimensions \\ OR: odds ratio \\ PHQ-9: Patient Health Questionnaire-9
}

\author{
Edited by G Eysenbach; submitted 30.03.17; peer-reviewed by T Irizarry, D Tao, H Devan; comments to author 10.08.17; revised \\ version received 03.10.17; accepted 02.11.17; published 19.04.18 \\ Please cite as: \\ Featherall J, Lapin B, Chaitoff A, Havele SA, Thompson N, Katzan I \\ Characterization of Patient Interest in Provider-Based Consumer Health Information Technology: Survey Study \\ J Med Internet Res 2018;20(4):e128 \\ URL: http://www.jmir.org/2018/4/e128/ \\ doi: $10.2196 /$ jmir.7766 \\ PMID: 29674312
}

(CJoseph Featherall, Brittany Lapin, Alexander Chaitoff, Sonia A Havele, Nicolas Thompson, Irene Katzan. Originally published in the Journal of Medical Internet Research (http://www.jmir.org), 19.04.2018. This is an open-access article distributed under the terms of the Creative Commons Attribution License (https://creativecommons.org/licenses/by/4.0/), which permits unrestricted use, distribution, and reproduction in any medium, provided the original work, first published in the Journal of Medical Internet Research, is properly cited. The complete bibliographic information, a link to the original publication on http://www.jmir.org/, as well as this copyright and license information must be included. 